\title{
Survey and Characterization of Botanical Pesticidal Plants in Ifugao
}

\author{
Teresita D. Allig \\ Ifugao State University, Lamut Campus(Email address: teresitaallig@yahoo.com)
}

\begin{abstract}
The harmful effects of inorganic or synthetic pesticides to human health and the environment has prompted many countries to search for more environmentally and toxicologically safe and more selective and efficacious pesticides. The study identified and described plants used by farmers in the control of pest, identified plant part/s used, their preparation and application. Data were gathered using an interview schedule.

Two hundred fifty (250) farmers from eight (8) municipalities of the province with knowledge and experienced on the use of botanical pesticides in their farms were the respondents

Result showed that there are 47 pesticide plants used by farmers distributed across municipalities for the control of agricultural pests. Gandoricum vidalii Mer fruits, are most frequently used in the control of golden apple snail while Croton oil plant (Mollustus philippinensis) fruits are most frequently used in the control of giant earthworms. Pesticide plants identified ranges from vines, herbs, shrubs, small to medium to tall trees mostly found in higher elevation.
\end{abstract}

Keywords: characterize, pesticide plants, survey

\section{Introduction}

\subsection{Rationale}

Insecticides had become one of the major expenses of farmers that account for about 40 percent of total production cost (America L. 2004)

But lately, the harmful effects of inorganic pesticides to the environment, humans, and livestock prompted various countries worldwide to ban the use of these pesticides and look for alternative replacements that are more environment-friendly and less harmful.

The shift from chemical pesticides to botanical pesticides is now gaining popularity. It promotes balanced and self-regulated agricultural systems. It is also less harmful to the environment, humans, and livestock and cost less to the farmers (L. America, 1998)

Tens of thousands of secondary products of plants have been identified and there are estimates that hundreds of thousands of these compounds exist. There is growing evidence that most of these compounds are involved in the interaction of plants with other species-primarily the defense of the plant from plant pests. Thus, these secondary compounds represent a large reservoir of chemical structures with biological activity. This resource is largely untapped for use as pesticides (Lydon J. 1988).

Ifugao is rich in natural resources, one of which is the diversity of plants in the mountains, forests, along the rivers and other places. Many plants in Ifugao are not yet discovered as to its economic importance, hence there is a need to find out plants with pesticidal content for conservation and future use in the production of safe and environmentally friendly pesticides. The study aims to; identify plants 
in Ifugao that has pesticidal content, determine the uses of these plants in relation to pests control, characterize these plants and their natural habitat.

The study was conducted in eight municipalities of Ifugao In each municipality, 5 barangays in each municipality were used as the study sites.

Farmers who have knowledge and have used these plants for pests control in their rice, corn and vegetable farm were the respondents in this study.

The study made use of the descriptive survey methods with the use of questionnaire as the instrument in gathering data. Stratified random sampling was conducted to at least 30 percent of farmers who have knowledge on pesticidal plants and have used it in their rice plants, vegetables and other plants in selected municipalities of Ifugao. Gathering data was done through face to face interviews. Data gathered were subjected to frequency count, averaging and percentage computation to determine the frequency of pesticidal plants as used by farmers.

\section{Research Methodology}

Sustainable agriculture's emphasis on increased crop diversity is a key factor in achieving food security and the presence of diverse crops on the farm had multiple benefits in alleviating hunger, and better environmental and income outcomes. With diversified and integrated farms, the risk of crop loss due to pests, diseases, and calamity is minimized since pest are crop-specific. Crop harvest is spread throughout the year, thus spreading income and food sources; and with more food grown on the farm, farming families are more self-reliant and food-secure (Bachmann et al. 2009)

Low yields combined with unsophisticated marketing systems in the Philippines keep farmers poor and threaten food security. Agriculture Industry needs to develop production systems that adequately meet

The use of low cost natural sources of fertilizers and botanicals such as wild sunflowers, Madre de Cacao, Indigenous Microorganisms (IMO), Fermented Fruit Juice (FPJ) or a combination of these would improve the fertility of the soil, increased yield to sustained food for the family. Wild sunflower leaves have high nitrogen content (2.9 percent oven dry weight) and that fresh sunflower leaves can give an equivalent of $60 \mathrm{~N} \mathrm{~kg} / \mathrm{ha}$. (Fernandez, 2002). Madre de Cacao leaves can provide $1.81 \% \mathrm{~N}$, $1.81 \%$ Phosphorus and $21.85 \%$ Potassium (IIRR, 1992). Fermented Fruit Juice is used as a foliar spray to enhance fruit quality and is generally used during the flowering and fruiting stage (Maghirang, 2011).

The Indigenous Microorganisms when applied fix atmospheric nitrogen for plant use, it also helps in the production of plant hormones (Umi and Sariah, 2006).

PhilRice researchers have found that wild sunflower leaves have high nitrogen content (2.9 percent oven dry weight) and that fresh sunflower leaves can give an equivalent of $60 \mathrm{~N} \mathrm{~kg} / \mathrm{ha}$. In rice seedbeds, wild sunflower is incorporated into the seedbed to serve as fertilizer for the rice seedlings. From 15 to 25 pieces of sunflower tops are needed to fertilize a square meter of the seedbed. In irrigated lowland rice paddy, sunflower is applied eight days before transplanting or during the last harrowing to maximize the nitrogen it releases. Aside from being locally available and for free, wild sunflower easily decomposes (7-10 days) and also hastens the decomposition of other weeds. In sloping mountains, it helps prevent soil erosion (DA-PhilRice, 2002).

In a study conducted by Wang et. al, Grain yield in integrated crop management (ICM) was $13.5 \%$ higher than in farmers' practice (FA). A maximum grain yield of 9.40 and $10.53 \mathrm{t}$ per hectare was achieved under ICM in the early and late season rice respectively. Yield improvement on doubleseason rice with ICM was achieved with combined effect of increased plant density and optimized nutrient management. 
Integrating fish in rice farming in the Philippines

Natural organic farming system is a technology in agriculture that uses environmentally sound techniques for crops that are free from most synthetic pesticides, growth hormones and fertilizers. Organic farming typically relies on pesticides and fertilizers derived from plants, animal waste, and minerals. They incorporate biological methods, such as the use of one organism to suppress another, to help control pests. The methods used in organic farming seek to increase soil fertility, balance insect population, and reduce air, soil and water population (Winter C. 2000).

Organic rice is fat free and has high carbohydrate content. Red and brown rice have higher fiber value than white rice. When 45 grams of organic rice is eaten, 160 calories of carbohydrates is consumed. Organic rice has low sugar content. Studies in North America show that the coarse grind and low sugar content of organically processed cereals and breads results in less tooth decay. When a child or adult eats a high sugar food item, the pancreas produces too much insulin, causing blood-sugar level to drop. This short change produces the brain of glucose which results in mood swings and an inability to concentrate (http://www. Phippscountry.com/ricelist.htm).

Botanical pesticides promotes balanced and self- regulated agricultural system, it is also less harmful to the environment, humans and livestock and cost less to the farmer (L. America, 1998).

Botanical pesticides are numerous in the province, in a research conducted by the proponent titled "Survey and Characterization of Botanical Pesticides in Ifugao", in one town alone there are about 38 botanicals found in which many farmers are not aware of its importance in agriculture.

\section{Results And Discussion}

\subsection{Major Pesticidal Plants Used by Farmers}

There are at least 47 pesticidal plants identified and used by farmers for the control of agricultural pests in Ifugao. Of the 47 plants, 15 are popularly used by farmers (Table 1).

TABLE I: Common Pesticidal Plants Used by Farmers in Ifugao, Number of Users, Pest Controlled and Parts Used.

\begin{tabular}{|l|c|l|l|}
\hline \multicolumn{1}{|c|}{ Pesticidal Plants } & Number of Users & \multicolumn{1}{c|}{ Pests Controlled } & \multicolumn{1}{c|}{ Parts Used } \\
\hline Sandoricum vidalii $M$. & 138 & Golden apple snail \& giant earthworms & Leaves \& Fruits \\
\hline Solanum verbascifolium & 59 & Leaf folders, armyworms, maggots \& stem borers & Leaves \& Stems \\
\hline Derris eriptica B. & 34 & Giant earthworms & Leaves \& stems \\
\hline Jatropha curcas L. & 33 & Earthworms, golden kuhol, pod borers & Fruits \& leaves \\
\hline Ardisia sp. & 24 & Golden apple snail & Leaves \\
\hline Equisetum ramosissimum D. & 23 & Rodent traps & Whole plant \\
\hline Ficus sp. & 18 & Leaf folders, armyworms, giant earthworms & Bark \\
\hline Datura metel L. & 13 & Armyworms, stemborers, cutworms & Whole plant \\
\hline Areca catechu L. & 12 & Rice bugs, leaf folders, armyworms & Fruits \\
\hline Crypsinus taeniatus & 12 & Cutworms, armyworms & Leaves \\
\hline Hoya pubicalyx M. & 11 & Army worms \& cutworms & Whole plant \\
\hline Erigeron sumatrensis & 11 & Army worms \& cutworms & Leaves \\
\hline Premma odorata B. & 11 & Leaffolders, armyworms, stemborers & Leaves \\
\hline Tabernaemontana pandacaque & 10 & Diamond backmoth, stem borers & Leaves \& fruits \\
\hline Marattia sp. & 10 & Leaffolders \& armyworms & Leaves \& stems \\
\hline
\end{tabular}

\subsection{Pesticidal Plants in Ifugao and How They are Used by Farmers}

Some farmers mixed 11 to 12 pesticidal plants, the leaves and stems are pounded and mixed with other pesticidal plants and place in dikes or just above the paddy. The smell kills the larvae of insect pests and repel flying insects of leaf folders, army worms and stem borers of rice according to farmer users. Some farmers chopped the leaves and stem and spread it in the paddy to control earthworms. Few farmers pound fruits, place them in the orifice where water flow. Pounded fruits are carried to the paddy to control golden kuhol. Some pound the pesticidal plants to extract juice and sprayed to rice 
plants to control tungro virus. Other farmers spray the extracted juice to vegetables and legumes to control diamond backmoth and podborers.

\subsection{Characterization of Pesticidal Plants in Ifugao}

\section{Family: PALMAE}

Scientific Name: Areca catechu L. var. catechu

Common Name: Betel Nut

Description:

A tree up to $13 \mathrm{~m}$ tall, $20 \mathrm{~cm}$ in diameter; trunk erect, slender, marked with annular scars. Leaves are pinnate, up to 3 meters long; petiole imbricate and sheathing; leaflets linear up to $90 \mathrm{~cm}$

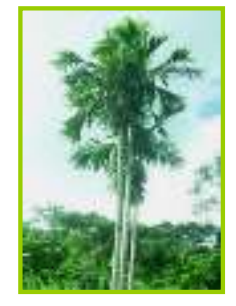
long. Inflorescence a spadix spreading twice or thrice branched. The fruit is drupe, ellipsoid and reddish yellow.

Pesticide Content: Alkaloids are abundant in the nuts and traces in the leaves.

Habitat: Cultivated in fields or in wooded thickets.

Distribution: Widely distributed in Province

Family: MILIACEAE

Scientific Name: Sandoricum vidalii Mer.

Common Name: Malasantol (Ilk)

Description: A large tree that can grow about 35 meters and a diameter of $100 \mathrm{~cm}$ or more. Twigs are glabrous with scattered lenticels. Bark is dark brown, leaves are pinnately compound, alternately scattered, glabrous, $15-20 \mathrm{~cm}$ long, petiole is rather slender; leaflets 10 or more, opposite, the basal ones are smaller. Fruits are similar with the santol fruit.

Pesticide content: Alkaloids $+1 \&$ Polyphenolic compounds +1

Habitat: Found in forest

Distribution: Not very numerous and found only in forest in medium to high altitudes.

Family: POLYPODIACEAE

Scientific Name: Crypsunus taeniatus(SW)

Description: An erect, succulent herb growing about $50 \mathrm{~m}$ tall, leaves growing from the base, linear with 6-7 leaves about 20-25 cm long and $5 \mathrm{~cm}$ wide, smooth with fleshy corm.

Pesticide content: Alkaloids +1 , Saponins +1 in leaves $\&$ stems

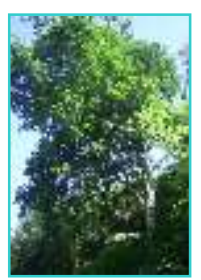

Habitat: Forest in cool places

Distribution: Abundant in cool moist forest in medium to high altitudes.

Family: FABACEAE

Scientific Name: Derris elliptica $B$.

Description: Vine that grows up to 20 meters, woody and stems are cylindrical, dark brown in color. Leaves are opposite with grayish color underneath, elliptically oblong up to $15 \mathrm{~cm}$ long and $8 \mathrm{~cm}$ wide.

Pesticide content: Saponins +2 \& Cyanogenic glycosides +2 stems \& leaves

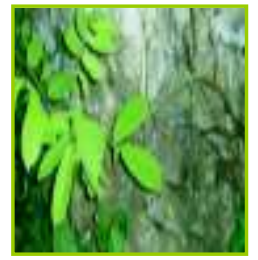


Habitat: Forest thickets in low and high elevation.

Distribution: Widely distributed in low, medium to high altitudes.

Family: EUPHORBIACEAE

Scientific Name: Jathropa Carcus

Common Name: Physic nut tree (Engl),

Description: A tree that grows up to $4 \mathrm{~m}$ tall. Leaves are broadly ovate, stipulate, base cordate, margins entire, apex accumulate to attenuate. Inflorescence a raceme. Flowers axillary, yellow, stigma lobed or club-shaped. Fruit a capsule.

Pesticide content: Alkaloids in stems, leaves \& fruits +2

Habitat: In wooded thickets.

Distribution: Found in all parts of the province.

Family: MARATHIACEAE

Scientific Name: Marattia sp.

Common Name: Dwarf thornless fern

Description: Dwarf fern that grows to about 1 meter tall, stipes green and stout. Fronds are 2-3 cm long, pinnae up to $80 \mathrm{~cm}$ long and $1 \mathrm{~cm}$ wide, margins crenulate. Sporangia about 8 -

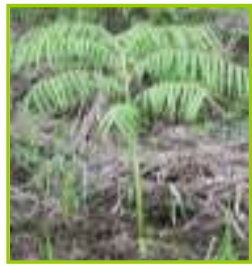
10. Stems are thornless.

Pesticide content: No pesticide content but slimy substances extracted from the stems are used to hold pounded botanicals together.

Habitat: Found in the thickets in most parts of the Philippines

Distribution: Widely distributed in medium to low altitudes

Family: SOLANACEAE

Scientific Name: Solanum verbascifolium L.

Common Name: Malatabako (Tag.),

Description : A shrub 1 to $4 \mathrm{~m}$ high, all parts stellate-pubescent. Leaves ovate or elliptic ovate 10 to $23 \mathrm{~cm}$ long, entire, acuminate, base is acute, somewhat rounded, lower surface pale

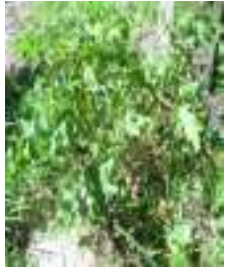
and densely pubescent. Cymas are terminal or sub-terminal, dichotomously compound, peduncled, and rather densely flowered. Calyz grayish green about $5 \mathrm{~mm}$ long. Corolla white, often tinged with green, lobes spreading about $1.3 \mathrm{~cm}$ in diameter.

Pesticide content: Alkaloids in leaves \& stems +2 , saponins in leaves +2

Habitat: Found in open lands, thickets, secondary forests, at low and medium altitudes.

Family: Solanaceae

Scientific Name: Datura metel L.

Common Name: Talong-punay (Tag.) Kamkamaulaw (Ilk) Thorn apple (Engl.)

Description: Coarse erect branched slightly hairy herb or short shrub about $2 \mathrm{~m}$ in height. Leaves ovate to oblong-ovate, 9 to $18 \mathrm{~cm}$ long inequilateral base pointed tip and irregularly and shallowly lobed margins. Flowers are very large, white or nearly purple, axillary, solitary.

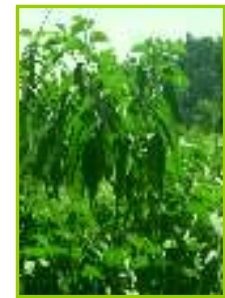
Calyx green about $6 \mathrm{~cm}$ long cleft at the apex and divided into linear teeth. Corolla is about $15 \mathrm{~cm}$ long, the mouth about $8 \mathrm{~cm}$ in diameter. Fruit rounded green about $3.5 \mathrm{~cm}$ in diameter covered with short stout spines. Seeds numerous, closely packed, nearly smooth pale brown. 
Habitat: Extensively cultivated throughout the Philippines

Distribution: Widely distributed in the ProvinceFamily:

Scientific Name: Tabernaemontana pandacaque

Common Name: Pandakaki puti (Tag)

Description: Erect, branched and smooth shrub, 1-3 meters high. Leaves are short-stalked, elliptical, canceolate to oblong-elliptic, 5-12 cm, narrowed at both ends; Inflorescences are axillary and terminal; the flowers are few. Calyx is green, ovoid and short. Corolla is white, slender-tubed, $1.7 \mathrm{~cm}$ long; limb is 2 to $2.5 \mathrm{~cm}$ in diameter, composed of 5 spreading, falcate, lanceolate lobes. Follicles are red oblong; $2-4 \mathrm{~cm}$ long and longitudinally ridged.

Pesticide content: Alkaloids in stems +3 , leaves +2

Habitat: Common in thickets at low altitude.

Distribution: Not abundant in low altitudes in the province.

Family: VERBENACEAE

Scientific Name: Premma subscandens Merr

Vernacular Name: Katingol

Description: A small tree about 5 to 6 meters tall, leaves are ovate and arrange opposite on its branches. Stems are cylindrical, green about $20 \mathrm{~cm}$ in diameter. Leaves are odorous.

Pesticide content: Alkaloids in stems \& leaves +2 , polyphenolic compounds +1

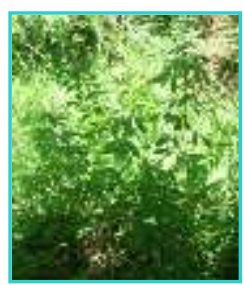

Habitat: Found throughout the Philippines

Distribution: Numerous in lower altitudes

Family: EQUISETACEAE

Scientific Name: Equisetum ramosissimum D.

Common Name: Horsetail

Description:The rhizomes are not tuberous. The shoots are all green and alike vegetatively, the sterile and cone-bearing shoots emerging at the same time. The main stems $30-50 \mathrm{~cm}$ high; grayish green; very rough to slightly rough (with scattered tubercles); bearing whorls of slender branches at the nodes at least on their lower halves. The main stem internodes swollen;

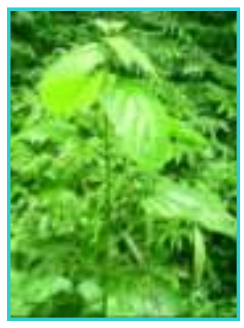
8-20 grooved; grooves moderately deep. The main stem internodes with a central hollow; central hollow about half the diameter of the internodes to more than half the diameter of the internodes (1/2 to $2 / 3)$; endodermis comprising two layers, one outside and the other inside the ring of vascular bundles. The main stem sheaths green at first, then brown with a black band at the bottom; about $8 \mathrm{~mm}$ long. The primary branches numerous. The first branch internodes is much shorter than the subtending sheaths (about a third its length). The primary branch internodes hollow. The stomata are sunken. The cones are 0.6-1.2 cm long; apiculate.

Pesticide content: Alkaloids in stems +2

Habitat: Found in rice fields, moist areas and in gardens

Distribution: Abundant in medium to high altitudes.

Family: ASCLEPADACEAE

Scientific Name: Hoya pubicalyx Merr

Vernacular Name: Haguyopyop 
Description: This is an erect, branched shrub 0.8 to 1.5 meters in height. The leaves are compound trifoliate elliptical in alternate arrangement in the stem. Stem is woody cylindrical and green in color. Leaves are small about 5 to $7.5 \mathrm{~cm}$ long and $2-3 \mathrm{~cm}$ wide, with oozing milky sap when cut (others have clear sap), waxy leaves, and showy clusters of blooms borne out of the thick flower stalk that resembles an upsidedown umbrella. Many of its species are scented.

Pesticide content: Alkaloids in stems and leaves +2 , Saponins in leaves +1

Habitat: In low and medium altitudes

Distribution: Widely distributed in Ifugao and the Philippines

Family: ASTERACEAE

Scientific Name: Erigeron sumatrensis

Vernacular Name: Laglagit

Description: A shrub about 1 to $3 \mathrm{~m}$ high. Leaves are ovate and serrated up to $20 \mathrm{~cm}$ long and $15 \mathrm{~cm}$ wide, with acute apex, midrib and veins prominent on the surface. Leaves are arranged alternately, smooth and dark green. Stems are green to light brown and rough.

Pesticide content: Alkaloids in stems \& leaves +2

Habitat: Found in the Forest.

Distribution: Not very abundant in medium to high altitudes.

Family: MYRSINACEAE

Scientific Name: Ardisia sp.

Vernacular Names: Chala'an (Mayoyao)

Description: A tall reaching, 20 to $25 \mathrm{~m}$ in height. Leaves are opposite, elliptical to ovate about $15 \mathrm{~cm}$ long; deep green and smooth, margins entire. Twigs and branches are rough and spiny.

Pesticide content: Alkaloids in leaves +1
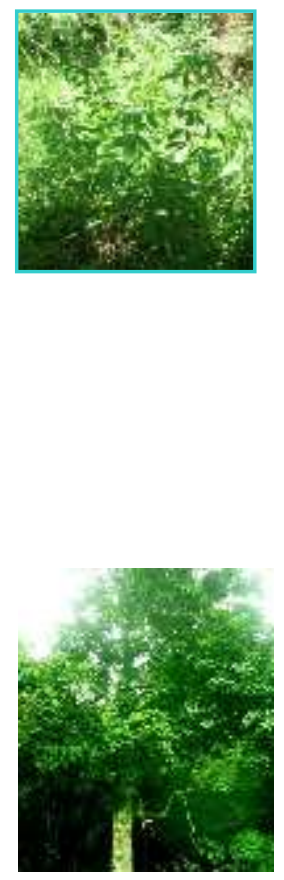

\section{Conclusion}

A survey of the pesticidal plants in Ifugao shows that there are numerous sources of potential botanical pesticides in the province. These plants has been tested and used by farmers and according to some they are effective while others say it is not so effective. Pagan farmer-users claimed that these plants are effective due to the rituals performed and not the plant by itself particularly for the control of insect pest of rice. There is therefore a need to conduct research on the effectiveness of these plants and developed preparation process that will improve the effectiveness of the botanical pesticides. These plants are capable of preventing, destroying, repelling, or mitigating any pests, pathogen or weed.

\section{Recommendations}

There is a need to determine the pesticidal content of these pesticidal plants by means of laboratory analysis. A laboratory and field evaluation of these pesticidal plants must be conducted in order to test its effectiveness against major pests of rice, corn, vegetables and other crops of economic importance in the province. 
A policy should be implemented by the local government to save and propagate these plants in their own habitat for future use by the farmers in order to minimize total dependency on synthetic pesticides which are harmful and toxic to the users and environment.

\section{References}

[1] America L. Agriculture: Plants as pesticides. MediaCore, PCARRD, Los Banos, Laguna, Philippines, 2000.

[2] Lydon J. Botanical Pesticides: Organic Pesticides and Biopesticides. Home \& Garden Information Center. California, U. S. A. 1988.

[3] Guazon C. B. Documentation and Collection of Pesticidal Plants in the Municipality of Hingyon, Ifugao. A Masteral Thesis, ISCAF, Lamut, Ifugao. 2004.

[4] Alberto A. P. Handbook on Trees. Philippine Copyright 2004, Rex Book Store, Inc. Philippines. 2004.

[5] Hensleigh T. E. Agro Forestry Species for the Philippines. U.S. Peace Corps Technology Support Center 2139 Fideal A. Reyes Stl. Malate, Manila Philippines, 1988.

[6] Madulid D. A. A Pictorial Guide to the Noteworthy Plants of Batanes Islands. UNESCO National Commission of the Philippines. Science and Technology Commission. Department of Foreign Affairs, 2330 Roxas Blvd., Pasay City, Philippines, 2006.

[7] Madulid D. A. Dictionary of Philippines Plant Names. Volume 1. 2007.

[8] Herbal Plants in the Philippines Handbooks.

[9] Razalan E. Cataloque of Indigenous Forestry Species in the Central Cordillera. Central Cordillera Agricultural Program (CECAP). Department of Agriculture, 2003.

[10] Salvosa F. M. Lexicon of Philippine Trees. Forest Products Research Institute, College, Laguna Philippines, 1963. 